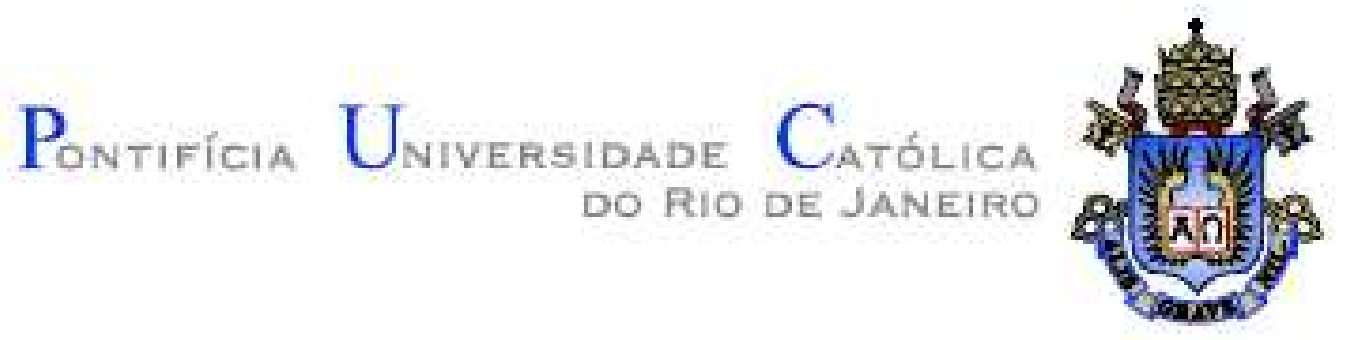

Roberto da Fonseca Junior

\title{
Medição do Campo Instantâneo de Velocidade do Líquido no Escoamento Bifásico Intermitente em Tubos Horizontais e Inclinados
}

Dissertação apresentada como requisito parcial para obtenção do título de Mestre pelo Programa de PósGraduação em Engenharia Mecânica da PUC-Rio.

Orientador: Prof. Luis Fernando Alzuguir Azevedo

Rio de Janeiro 


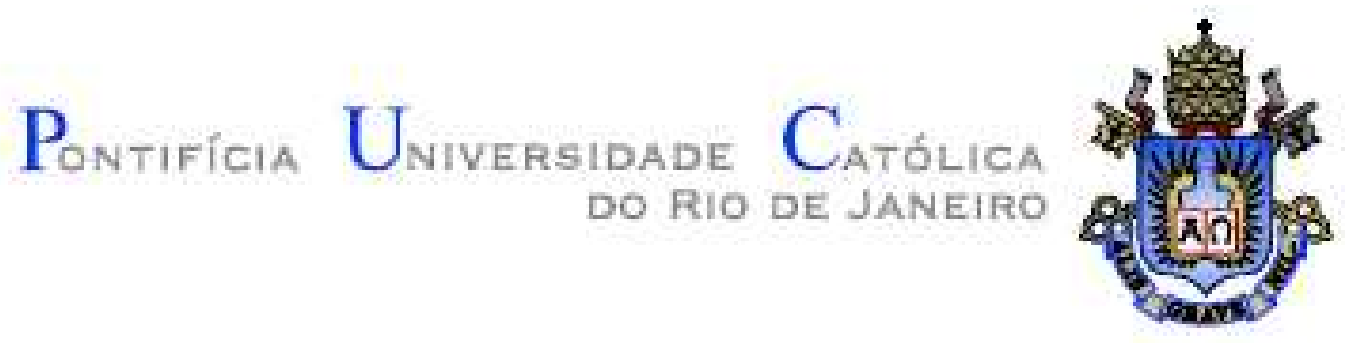

Roberto da Fonseca Junior

\author{
Medição do Campo Instantâneo de \\ Velocidade do Líquido no Escoamento \\ Bifásico Intermitente em Tubos Horizontais \\ e Inclinados.
}

Dissertação apresentada como requisito parcial para obtenção do título de Mestre pelo Programa de PósGraduação em Engenharia Mecânica da PUC-Rio. Aprovada pela Comissão Examinadora abaixo assinada.

Prof. Luis Fernando Alzuguir Azevedo

Orientador

Pontifícia Universidade Católica do Rio de Janeiro

Prof. Geraldo Afonso Spinelli Martins Ribeiro PETROBRAS

Prof. Sidney Stuckenbruck Olympus Software Científico e Engenharia

Dr. José Roberto Fagundes Netto

PETROBRAS

Prof. José Eugenio Leal Coordenador(a) Setorial do Centro

Técnico Científico - PUC-Rio

Rio de Janeiro, 03 de setembro de 2009 
Todos os direitos reservados. É proibida a reprodução total ou parcial do trabalho sem autorização da universidade, do autor e do orientador.

\section{Roberto da Fonseca Junior}

Graduou-se em Engenharia Química na Universidade Federal do Rio de Janeiro e especializou-se em Engenharia de Petróleo na Petrobras, onde trabalha com Garantia de Escoamento e Escoamento Multifásico.

Ficha Catalográfica

\begin{tabular}{|} 
Fonseca Junior, Roberto da \\
Medição do campo instantâneo de velocidade do \\
líquido no escoamento bifásico intermitente em tubos \\
horizontais e inclinados / Roberto da Fonseca Junior; \\
orientador: Luis Fernando Alzuguir Azevedo. - 2009. \\
206 f. : il. (color.) ; $30 \mathrm{~cm}$ \\
Dissertação (Mestrado em Engenharia \\
Mecânica)-Pontifícia Universidade Católica do Rio de \\
Janeiro, Rio de Janeiro, 2009. \\
Inclui bibliografia \\
1. Engenharia mecânica - Teses. 2. Escoamento \\
intermitente. 3. Velocimetria por imagem de partículas. 4. \\
Escoamento bifásico. I. Azevedo, Luis Fernando Alzuguir. \\
II. Pontifícia Universidade Católica do Rio de Janeiro. \\
Departamento de Engenharia Mecânica. III. Título.
\end{tabular}

CDD: 621 


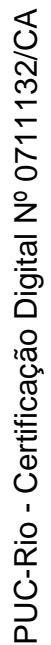

Aos meus pais, Roberto e Nely e minha esposa Renata, pelo apoio e confiança. 


\section{Agradecimentos}

Ao Professor Luis Fernando A. Azevedo pela orientação e dedicação que contribuíram para o sucesso no desenvolvimento deste trabalho.

Aos meus pais, os quais exerceram papel fundamental na minha educação e na formação do meu caráter.

À minha esposa Renata pelo amor, compreensão e solidariedade que me deram força para superar todas as dificuldades ao longo deste período.

À Petrobras pelo patrocínio e à PUC-Rio pela infra-estrutura, sem os quais este trabalho não poderia ter sido realizado.

Aos amigos que conquistei no laboratório de Engenharia Mecânica, pela disposição em ajudar em todos os momentos.

Aos meus colegas da Petrobras pelo companheirismo e ajuda diária. 


\section{Resumo}

Fonseca Jr, Roberto; Azevedo, Luis Fernando A. Medição do Campo Instantâneo de Velocidade do Líquido no Escoamento Bifásico Intermitente em Tubos Horizontais e Inclinados. Rio de Janeiro, 2009. 206p. Dissertação de Mestrado - Departamento de Engenharia Mecânica, Pontifícia Universidade Católica do Rio de Janeiro.

No presente trabalho foi realizado um estudo experimental sobre escoamento bifásico em regime intermitente através de tubos horizontais e de pequena inclinação, com o objetivo de determinação dos campos de velocidade instantâneos nas regiões a montante do nariz, a jusante da cauda das bolhas de gás, assim como na região do filme de líquido sob as bolhas. Foi implementada uma combinação de três técnicas ópticas não invasivas. Velocimetria por Imagem de Partículas bi-dimensional (Particle Image Velocimetry - PIV) foi utilizada para determinar os campos de velocidade instantâneos nas regiões de interesse, enquanto luz de fundo pulsada e sincronizada proveniente de uma matriz de LED's vermelhos iluminava os contornos das bolhas aumentando o contraste das interfaces líquido-gás (Pulsed Shadow Technique - PST). Uma técnica baseada na fluorescência induzida por laser foi utilizada (Laser Induced Fluorescence - LIF) para separar a luz verde intensa proveniente do laser associado à técnica PIV. Os testes foram conduzidos em seção transparente tendo água e ar como fluidos de trabalho. Os resultados obtidos revelaram informações detalhadas sobre o escoamento de líquido no escoamento intermitente. Foram produzidos também resultados estatísticos de algumas variáveis globais do escoamento como, a velocidade e os comprimentos das bolhas e pistões de líquido, além da frequência de passagem desta estruturas do escoamento.

\section{Palavras-chave}

Escoamento Intermitente; Análise Estatística; Velocimetria por Imagem de Partículas; Escoamento Bifásico; Campo de Velocidade. 


\section{Abstract}

Fonseca Jr, Roberto; Azevedo, Luis Fernando A. Instantaneous liquid velocity field measurements in two-phase intermittent flow through horizontal and inclined pipes. Rio de Janeiro, 2009. 206p. Msc Dissertation - Departamento de Engenharia Mecânica, Pontifícia Universidade Católica do Rio de Janeiro.

The present work was aimed at providing detailed information on the instantaneous liquid velocity fields at the film, nose and tail regions of slugs in horizontal and inclined two phase flow. To this end, a combination of three nonintrusive optical techniques was employed. Two-dimensional particle image velocimetry (PIV) was used to measure the instantaneous liquid velocity field at a meridional plane of the horizontal pipe test section, while a synchronized pulsed back lighting, provided by a matrix of red LED's, illuminated the bubble contours thereby enhancing contrast of the interfaces (Pulsed Shadow Technique - PST). A laser-induced fluorescence technique (LIF) was employed to separate the strong reflections coming from the gas-liquid interfaces produced by the green PIV laser, The tests were conducted on a specially built transparent pipe test section, using air and water as the working fluids. The velocity fields were obtained for flow regimes where the slugs were lightly aerated. The velocity field results in the nose, tail and film regions revealed valuable detailed information that helped to better understand the physics of the flow, besides contributing to the formation of a data bank for supporting the development of two-phase, horizontal slug flow simulations. The work conducted also provided statistical information on the main global variables that characterize the flow, such as, speed and length of gas bubbles and liquid slugs, and the frequency of passage of these structures.

\section{Keywords}

Slug flow; PIV; Two-phase flow; Velocity Field. 


\section{Sumário}

1 Introdução 26

1.1. Classificação dos padrões de escoamento 27

1.2. Mapas dos padrões de escoamento 31

1.3. Determinação experimental dos padrões de escoamento 34

1.4. Técnicas de medição específicas aplicadas em escoamento $\begin{array}{ll}\text { multifásico } & 37\end{array}$

1.5. Objetivo 39

1.6. Organização do trabalho $\quad 40$

2 Revisão da Literatura $\quad 41$

2.1. Descrição Teórica 41

2.1.1. Definição de variáveis $\quad 41$

2.1.2. Estimativa da perda de carga 44

2.1.3. Velocidade de propagação da bolha 45

2.1.4. Hold up de líquido 46

2.1.5. Comprimento do pistão de líquido. 46

2.1.6. Frequência dos slugs. $\quad 47$

2.2. Modelagem do Escoamento 48

2.3. Trabalhos Experimentais 51

2.3.1. Velocidade de propagação das bolhas 52

2.3.2. Distribuição de comprimento das bolhas e pistões 58

2.3.3. Visualizações e medições experimentais do perfil de velocidade da fase líquida $\quad 61$ 
3 Técnica de Medição $\quad 73$

3.1. Velocimetria por imagem de partícula (PIV) 74

3.1.1. Subsistema de iluminação $\quad 77$

3.1.2. Plano de luz laser $\quad 78$

$\begin{array}{ll}\text { 3.1.3. Partículas traçadoras } & 79\end{array}$

3.1.4. Subsistema de aquisição de imagens $\quad 80$

3.1.5. Sincronizador 82

3.1.6. Análise das imagens 83

3.1.7. Detecção dos picos de correlação 85

$\begin{array}{ll}\text { 3.1.8. Pós-Processamento } & 87\end{array}$

3.2. Fluorescência induzida por laser (LIF) 88

3.3. Iluminação pulsada de fundo (PST) 90

3.4. Aquisição de parâmetros globais do escoamento $\begin{array}{ll}\text { através de sistema de interruptores de feixe. } & 91\end{array}$

4 Montagem Experimental $\quad 93$

4.1. Sistema de escoamento da água 94

4.2. Sistema de escoamento de ar 96

4.3. Seção de testes $\quad 96$

4.3.1. Tanque de separação 98

4.3.2. Medição de temperatura 99

4.3.3. Sistema PIV $\quad 99$

$\begin{array}{ll}\text { 4.3.3.1. Laser } & 100\end{array}$

4.3.3.2. Câmera digital 100

$\begin{array}{ll}\text { 4.3.3.3. Sincronizador } & 100\end{array}$

$\begin{array}{ll}\text { 4.3.3.4. Conjunto de lentes } & 101\end{array}$

4.3.3.5. Caixa de visualização 101

$\begin{array}{ll}\text { 4.3.3.6. Partículas } & 102\end{array}$

4.3.3.7. Painel de LED’s e placa difusora 102 
$\begin{array}{ll}\text { 4.3.3.8. Filtro } & 103\end{array}$

$\begin{array}{ll}\text { 4.3.3.9. Sistema de interruptores de feixe } & 104\end{array}$

5 Procedimento Experimental 105

5.1. Princípio de funcionamento conjunto das técnicas

LIF, PST e PIV 105

5.2. Procedimento para aquisição sincronizada das imagens 106

5.3. Processamento das imagens 107

5.4. Processamento dos vetores instantâneos de velocidade 113

5.5. Cálculo do perfil médio de velocidade e velocidade

$\begin{array}{ll}\text { de propagação da bolha } & 113\end{array}$

5.6. Aquisição dos parâmetros globais do escoamento

intermitente utilizando o sistema de interruptores de feixe. 114

5.6.1. Cálculo das velocidades 118

5.6.2. Cálculo dos comprimentos 119

5.6.3. Período e freqüência dos slugs 119

5.6.4. Critério de Chauvenet e fator de corte para velocidade $\begin{array}{ll}\text { de propagação das bolhas } & 120\end{array}$

5.6.5. Cálculo dos valores médios e desvio padrão dos resultados 121

6 Resultados 122

6.1. Matriz de testes 122

6.2. Velocidade de propagação das bolhas 123

6.3. Análise estatística das variáveis globais do escoamento $\begin{array}{ll}\text { intermitente } & 126\end{array}$

$\begin{array}{ll}\text { 6.3.1. Velocidade das bolhas } & 126\end{array}$

6.3.2. Comprimento das bolhas 131

6.3.3. Velocidade da cauda da bolha (Velocidade do pistão de líquido) 134

6.3.4. Comprimento do pistão de líquido. 139 
6.3.5. Frequência dos slugs. 145

6.4. Resultados de campos de velocidade na fase líquida 147

6.4.1. Velocidades instantâneas no referencial do laboratório 148

6.4.1.1. Região do nariz da bolha 148

6.4.1.2. Região da esteira da bolha 152

6.4.2. Campo instantâneo de velocidade no referencial da $\begin{array}{ll}\text { bolha em movimento } & 156\end{array}$

$\begin{array}{ll}\text { 6.4.3. Perfis de velocidade média } & 167\end{array}$

6.4.3.1. Comparação dos perfis médios com perfil teórico 168

6.4.3.2. Perfis transversais da velocidade média no filme na $\begin{array}{ll}\text { direção axial } & 171\end{array}$

6.4.3.3. Perfis transversais da velocidade transversal média no filme 177

6.4.4. Extração das velocidades e grandezas turbulentas 188

7 Conclusão 194

8 Referências Bibliográficas 197

$\begin{array}{ll}\text { Apêndice } & 202\end{array}$

A. Avaliação das incertezas de medição 202

A.1. Incerteza da vazão medida pelo rotâmetro. 202

A.2. Incerteza da medição da velocidade de deslocamento

da bolha e do pistão. 203

A.3. Incerteza na medição do comprimento da bolha e do pistão. 205 


\section{Lista de Figuras}

Figura 1.1 - Padrões do escoamento para tubulações na posiçãovertical 28 Figura 1.2 - Padrões do escoamento para tubulações na horizontal ou pouco inclinado

Figura 1.3 - Mapa de padrões de escoamento horizontal proposto por Spedding \& Nguyen (1980).

Figura 1.4 - Mapa de padrões de escoamento horizontal proposto por Baker (1954).

Figura 1.5 - Mapa de padrão de escoamento para escoamento horizontal (Mandhane et al 1974).

Figura 1.6 - Distribuição da voltagem ao longo do tempo para os diferentes padrões de escoamento no escoamento horizontal bifásico.

Figura 1.7 - Esboço do sensor wire-mesh (Prasser et al 1998).

Figura 1.8 - Variação temporal da fração de vazios a partir da técnica de wire mesh na seção transversal do duto.

Figura 2.1 - Representação do escoamento intermitente com algumas das suas variáveis a serem estudadas.

Figura 2.2 - Perfis de velocidade no pistão de líquido (Taitel \& Barnea, 1990)

Figura 2.3 - Modelo de célula unitária para modelagem do padrão de escoamento intermitente horizontal e pouco inclinado.

Figura 2.4 - Região de medição feita por Kvernvold et al (1984).

Figura 2.5 - Variação da velocidade na porção inferior da tubulação (Kvernvold et al 1984).

Figura 2.6 - Perfil de velocidade no filme a $180 \mathrm{~mm}$ distante do início da bolha (Kvernvold et al 1984).

Figura 2.7 - Estrutura do escoamento da fase líquida durante escoamento intermitente horizontal (Kawaji 1998)

Figura 2.8 - Desenvolvimento do perfil de velocidade do pistão antes da chegada da bolha (Sharma et al 1998).

Figura 2.9 - Desenvolvimento do perfil de velocidade do pistão após a passagem da bolha (Sharma et al 1998). 
Figura 2.10 - Fração de vazios ("void fraction"), velocidade média ( $\mathrm{u}_{\mathrm{ave}}$ ) e intensidade turbulenta segundo Lewis et al 2002. (a) ULS $=1.65 \mathrm{~m} / \mathrm{s}$ e UGS $=0.55 \mathrm{~m} / \mathrm{s} ;$ (b) ULS $=1.65 \mathrm{~m} / \mathrm{s}$ e UGS $=1.1 \mathrm{~m} / \mathrm{s}$; (c) ULS $=1.65 \mathrm{~m} / \mathrm{s}$ e UGS $=2.2 \mathrm{~m} / \mathrm{s}$

Figura 2.11 - Perfis de velocidade axial e radial à uma distância de 2,2D à frente da bolha de gás (Gomez 2003)

Figura 2.12 - Perfis de velocidade na direção axial no filme de líquido (Gomez 2003).

Figura 2.13 - Perfis de velocidade na direção radial na região do filme (Gomez 2003).

Figura 2.14 - Desenvolvimento da velocidade no pistão na direção axial (Gomez 2003).

Figura 2.15 - Desenvolvimento da velocidade no pistão na direção radial (Gomez 2003).

Figura 3.1 - Princípio de funcionamento da técnica PIV.

(Fonte: www.dantecdynamics.com)

Figura 3.2 - Exemplo de para de imagens obtidas para utilização da técnica PIV (a) Instante t=to. (b) Instante t=to+ $\Delta$ t (Aniceto P.H. 2007). 76 Figura 3.3 - Esquema de laser Nd:YAG e seus componentes (Barros J.M. 2007)

Figura 3.4 - Diagrama de lentes para formação do plano de luz com um laser (Aniceto P.H. 2007).

Figura 3.5 - Luz espalhada por uma partícula esférica de vidro diâmetro de (a) $1 \mu \mathrm{m}$ e (b) $10 \mu \mathrm{m}$, comprimento de onda da luz incidente $\lambda=532 \mathrm{~nm}$ (http://www.philiplaven.com/mieplot.htm).

Figura 3.6 - Sensor de CCD utilizados nas câmeras de PIV

(Barros J.M. 2007)

Figura 3.7 - Diagrama temporal de sincronismo entre o laser e a câmera (Aniceto, P.H. 2007).

Figura 3.8 - Diagrama temporal de sincronismo entre o laser e a câmera operando no modo frame straddling (Aniceto, P.H. 2007)

Figura 3.9 - Resumo ilustrativo da técnica de correlação cruzada (Raffel et al 2007).

Figura 3.10 - Utilização da FFT para agilizar o processo de correlação cruzada (Raffel et al 2007).

Figura 3.11 - Deslocamento da partícula. 
Figura 3.12 - Mapa típico do coeficiente de correlação, $R$, para correlação cruzada. (fonte: Almeida 1997). 86

Figura 3.13 - Diagrama de Jablonski. 89

Figura 3.14- Espectro de absorção e fluorescência

(Fonte: Thermo Scientific). 90

Figura 3.15 - Desenho esquemático da técnica PST

(Aniceto P.H 2007).

Figura 3.16 - Princípio de funcionamento do interruptor de feixe 92

Figura 4.1 - Visão geral do aparato experimental 93

Figura 4.2 - Visão do aparato experimental inclinado. 94

Figura 4.3 - Curva de operação da bomba utilizada

nos experimentos. Fonte: (www.weatherford.com) 95

Figura 4.4 - Fluxo de entrada e saída no misturador. 96

Figura 4.5 - Perfil Bosch $45 \times 45$ utilizado para apoio do tubo. 97

Figura 4.6 - Estrutura de metalon para apoio do perfil Bosch

onde a tubulação foi montada. $\quad 97$

Figura 4.7 - Desenho esquemático da base central e um dos

suportes situados nas extremidades. 98

Figura 4.8 - Tanque de separação 99

Figura 4.9 - Elementos constituintes da metodologia de

medição do PIV. $\quad 100$

Figura 4.10 - Caixa de visualização. Dimensões em milímetros. 101

Figura 4.11 - LED vermelho de $5 \mathrm{~mm}$ (Fonte: Site Farnell) e

painel com LED's . 102

Figura 4.12 - Placa difusora do painel de LED's 103

Figura 4.13 - (a) Filtro OG 570 (Fonte: site www.mellesgriot.com).;

(b) Curva de Transmissividade do filtro Óptico (Fonte: site www.mellesgriot.com) 103

Figura 4.14 - Destaque ao sistema de interruptores de feixe. 104

Figura 4.15 - Equipamento interruptor de feixe e seu cabo de

alimentação (Fonte: www.pasco.com) 104

Figura 5. 1 - Princípio de funcionamento do sistema combinado

PIV/PST/LIF (esquema adaptado de Carpintero et al 2006). 106

Figura 5.2 - Imagem referência original (a) e após utilização do filtro $\begin{array}{ll}\text { mediana (b). } & 108\end{array}$

Figura 5.3 - Apresentação das imagens A e B antes do processamento. 108 
Figura 5.4 - Imagem original B antes (a) e após passagem do filtro mediana (b).

Figura 5.5 - resultado da subtração entre a imagem com a bolha e a imagem de referência.

Figura 5.6 - Resultado após binarização, delimitação da região de presença de líquido, antes (a) e depois da inversão dos valores da região da bolha e do líquido (b).

Figura 5.7 - Resultado após subtração (a) e realce nas partículas (b). 110

Figura 5.8 - Imagem B final após processamento completo. 111

Figura 5.9 - Resultado da multiplicação das imagens

Figura 5.10 - (a) Imagem binarizada; (b) Imagem final para processamento do PIV.

Figura 5.11 - Par de imagens final após o procedimento de processamento das imagens.

Figura 5.12 - (a) Sensor de interruptor de feixe; (b) Localização dos sensores na seção de teste.

Figura 5.13 - Representação gráfica da resposta dos sensores de infravermelho à passagem das bolhas e pistões de líquido.

Figura 5.14 - Representação gráfica da resposta dos sensores de infravermelho à passagem das bolhas, em um escoamento com pistão aerado.

Figura 5.15 - Sinais originais enviados pelo sistema de interruptores de feixe, antes da utilização do filtro.

Figura 5.16 - Resultado após passagem de filtro

Figura 5.17 - Definição da nomenclatura para o cálculo dos parâmetros globais do escoamento.

Figura 6.1 - Identificação dos pontos de teste no mapa de padrões de escoamento água e ar em tubos com diâmetro de 1 polegada, segundo Mandhane et al 1974.

Figura 6.2 - Comparação entre resultados de medição de velocidade de bolhas para escoamento horizontal $(\mathrm{Frm}<2)$.

Figura 6.3 - Comparação entre resultados de medição de velocidade de bolhas para escoamento inclinado ( +5 graus em todos os casos) para $($ Frm $<2)$.

Figura 6.4 - Comparação da velocidade média de propagação das bolhas para os casos horizontal e inclinado a $5^{\circ}$. 
Figura 6.5 - Comparação do desvio padrão da velocidade de propagação das bolhas para os casos horizontal e inclinado a $5^{\circ}$.

Figura 6.6 - Distribuição de probabilidade das velocidades das bolhas para o escoamento horizontal.

Figura 6.7 - Distribuição de probabilidade das velocidades das bolhas para o escoamento inclinado a $5^{\circ}$.

Figura 6.8 - Distribuição de probabilidade dos comprimentos das bolhas no escoamento horizontal.

Figura 6.9 - Distribuição de probabilidade dos comprimentos das bolhas para o escoamento inclinado a $5^{\circ}$.

Figura 6.10 - Distribuição de probabilidade da velocidade dos pistões de líquido para escoamento horizontal.

Figura 6.11 - Distribuição de probabilidade da velocidade dos pistões de líquido para escoamento inclinado a $5^{\circ}$.

Figura 6.12 - Comportamento do comprimento do pistão de íquido para o escoamento horizontal e inclinado.

Figura 6.13 - Distribuição de probabilidade de comprimentos do pistão para escoamento horizontal.

Figura 6.14 - Distribuição de probabilidade para comprimentos do pistão para escoamento inclinado a 50 .

Figura 6.15 - Comparação entre a frequência de passagem e a velocidade superficial de líquido.

Figura 6.16 - Comparação dos resultados para frequência de passagem de slugs com os resultados de Duarte (2007) para tubo horizontal.

Figura 6.17 - Campo instantâneo de velocidade de líquido na região do nariz da bolha para escoamento horizontal. Escala de cores representa o módulo da velocidade.

Figura 6.18 - Campo instantâneo de velocidade de líquido na região do nariz da bolha para escoamento inclinado. Escala de cores representa o módulo da velocidade.

Figura 6.19 - Campo instantâneo de velocidade de líquido na região da cauda da bolha para escoamento horizontal. Escala de cores representa o módulo da velocidade.

Figura 6.20 - Campo instantâneo de velocidade de líquido na região da cauda da bolha para escoamento inclinado. Escala de cores representa o módulo da velocidade. 
Figura 6.21 - Teste 5, escoamento inclinado. Ampliação da região inferior do tubo mostrando zona de recirculação do escoamento.

Figura 6.22 - Resultados para os campos instantâneos de velocidade do líquido na região do nariz da bolha, medidos em relação ao referencial da bolha para tubo horizontal. Escala de cores representa a velocidade na direção axial subtraída da velocidade da bolha.

Figura 6.23 - Resultados para os campos instantâneos de velocidade do líquido na região do nariz da bolha, medidos em relação ao referencial da bolha para tubo inclinado. Escala de cores representa a velocidade na direção axial subtraída davelocidade da bolha.

Figura 6.24 - Campo instantâneo de velocidade de líquido na região da cauda da bolha - esc. horizontal referencial em movimento. Escala de cores representa a velocidade na direção axial subtraída da velocidade da bolha.

Figura 6.25 - Campo instantâneo de velocidade de líquido na região da cauda da bolha - esc. inclinado referencial em movimento. Escala de cores representa a velocidade na direção axial subtraída da velocidade da bolha.

Figura 6.26 - Resultados para os campos instantâneos de velocidade do líquido na região do nariz da bolha, medidos em relação ao referencial da bolha para tubo horizontal. Escala de cores representa a velocidade na direção axial subtraída da velocidade da bolha.

Figura 6.27 - Resultados para os campos instantâneos de velocidade do líquido na região do nariz da bolha, medidos em relação ao referencial da bolha para tubo inclinado. Escala de cores representa a velocidade na direção axial subtraída da velocidade da bolha.

Figura 6.28 - Campo instantâneo de velocidade de líquido na região da cauda da bolha - esc. horizontal referencial em movimento. Escala de cores representa a velocidade na direção axial subtraída da velocidade da bolha. 
Figura 6.29 - Campo instantâneo de velocidade de líquido na região da cauda da bolha - esc. inclinado referencial em movimento. Escala de cores representa a velocidade na direção axial subtraída da velocidade da bolha.

Figura 6.30 - llustração da posição axial onde foram computados perfis de velocidade média.

Figura 6.31 - Comparação do perfil analítico de velocidade para escoamento turbulento hidrodinamicamente desenvolvido e os perfis medidos experimentalmente no presente, trabalho para tubo horizontal e inclinado.

Figura 6.32 - Perfis de velocidade axial médio no filme de líquido para escoamento horizontal.

Figura 6.33- Perfis de velocidade axial médio no filme de líquido para escoamento inclinado.

Figura 6.34 - Perfil de velocidade axial na região do pistão para os testes realizados no escoamento horizontal.

Figura 6.35 - Perfis de velocidade axial na região do pistão para os testes realizados no escoamento inclinado.

Figura 6.36 - Perfis de velocidade transversal na região do filme de líquido para escoamento horizontal.

Figura 6.37 - Perfis de velocidade transversal na região do filme de líquido para escoamento inclinado.

Figura 6.38 - Perfis de velocidade transversal média na região do pistão de líquido para escoamento horizontal.

Figura 6.39- Perfis de velocidade transversal média na região do pistão de líquido para escoamento inclinado.

Figura 6.40 - Estrutura do escoamento horizontal intermitente analisando sob o ponto de vista do referencial estático (figura baseada em Kawaji 1998).

Figura 6.41 - Estrutura do escoamento inclinado intermitente analisando sob o ponto de vista do referencial estático (figura baseada em Kawaji 1998).

Figura 6.42 - Estrutura do escoamento horizontal intermitente analisando sob o ponto de vista do referencial em movimento (baseado em Kawaji 1998). 
Figura 6.43 - Estrutura do escoamento inclinado intermitente analisando sob o ponto de vista do referencial em movimento (baseado em Kawaji 1998).

Figura 6.44 - Flutuação da velocidade na região do filme de líquido para escoamento horizontal.

Figura 6.45 - Flutuação da velocidade na região do pistão de líquido para escoamento horizontal.

Figura 6.46 - Intensidade Turbulenta na região do filme de líquido para escoamento horizontal.

Figura 6.47 - Intensidade Turbulenta na região do pistão de líquido para escoamento horizontal. 


\section{Lista de Tabelas}

Tabela 2.1 - Resultados observados por Bendiksen (1984) para as constantes $\mathrm{C}_{0}$ e $\mathrm{u}_{\mathrm{d}}$ em escoamento horizontal e inclinado a 5 graus. 54

Tabela 2.2- Resultados observados por Cook \& Behnia (2001).

Tabela 2.3 - Constante $\mathrm{C}_{0}$ para viscosidades diferentes, segundo

Duarte 2007.

Tabela 2.4 - Resumo dos trabalhos experimentais de medição de velocidade de propagação da bolha citados.

Tabela 2.5 - Resumo dos trabalhos experimentais de análise estatística das variáveis globais do escoamento intermitente citados anteriormente.

Tabela 2.6 - Regiões do escoamento de líquido verificadas após a passagem do pistão.

Tabela 2.7 - Resumo dos trabalhos experimentais de medição do perfil de velocidade.

Tabela 4.1 - - Incerteza do rotâmetro de líquido OMEL modelo 182932 utilizado nos experimentos.

Tabela 6.1- Matriz dos testes realizados

Tabela 6.2 - Velocidade de propagação das bolhas para escoamento horizontal e inclinado a 5 graus.

Tabela 6.3 - Constantes C0 e ud para escoamento horizontal e inclinado após medição do presente trabalho.

Tabela 6.4 - Resumo dos resultados experimentais para $\mathrm{C}_{0}$ e $\mathrm{u}_{\mathrm{d}} \mathrm{da}$ literatura.

Tabela 6.5 - Resultados de medição da velocidade média de propagação das bolhas para escoamento horizontal.

Tabela 6.6 - Resultados de medição da velocidade média de propagação das bolhas para escoamento inclinado a $5^{\circ}$.

Tabela 6.7 - Resultados de medição do comprimento médio das bolhas para escoamento horizontal.

Tabela 6.8 - Resultados de medição do comprimento médio das bolhas para escoamento inclinado a 50 .

Tabela 6.9 - Velocidade média e desvio padrão dos pistões para escoamento horizontal. 
Tabela 6.10 - Velocidade média e desvio padrão dos pistões para escoamento inclinado.

Tabela 6.11 - Relação entre a velocidade medida do nariz da bolha e a velocidade medida de sua cauda.

Tabela 6.12 - Comprimento médio e desvio padrão do comprimento do pistão de líquido para escoamento horizontal

Tabela 6.13 - Comprimento médio e desvio padrão do comprimento do pistão de líquido para escoamento inclinado a $5^{\circ}$.

Tabela 6.14 - Resultados para comprimento médio do pistão de líquido encontrados na literatura.

Tabela 6.15 - Coeficiente de correlação entre o comprimento do pistão e líquido e a velocidade da bolha.

Tabela 6.16 - Comparação com valores de correlações da literatura para escoamento horizontal. 


\section{Lista de Variáveis}

\section{Letras Latinas}

A - Área da seção transversal do tubo

c - Velocidade da luz

$\mathrm{C}_{0}$ - Constante da equação para o cálculo de $\mathrm{u}_{\mathrm{t}}$

D - Diâmetro interno da tubulação

E - Energia

$E_{o}$ - Número de Eötvös

$\mathrm{f}$ - Distância focal

$\mathrm{f}_{\mathrm{s}}$ - Frequência dos slugs

$\mathrm{Fr}_{\mathrm{m}}$ - Número de Froude da mistura

$\mathrm{g}$ - Aceleração gravitacional

h - Constante de Planck

I - Intensidade Turbulenta

$L$ - Distância entre as sondas

$\mathrm{L}_{\text {crit }}$ - Comprimento crítico do pistão

$\mathrm{L}_{f}$ - Comprimento do filme de líquido

$L_{S}$ - Comprimento do pistão de líquido

$L_{U}$ - Comprimento da "célula unitária" ou unidade slug

M - Fator de Magnificação

$\mathrm{N}$ - número de bolhas

Q - Vazão volumétrica

Re - Número de Reynolds

$\mathrm{R}_{\|}-$Função de correlação cruzada

$\mathrm{R}(\mathrm{x}, \mathrm{y})$ - Coeficiente de correlação

$\mathrm{R}_{S}$ - Fração de líquido na região do pistão

$S$ - Escorregamento

SI - Sistema Internacional de Unidades

$\mathrm{t}$ - Tempo

T - Tempo indicativo de chegada de bolha ou pistão nos interruptores de feixe.

$t_{0}$ - Tempo inicial

$\mathrm{T}_{\mathrm{n} 1, \mathrm{n}}$ - Tempo de chegada do nariz da bolha $\mathbf{n}$ no canal $\mathbf{1}$;

$\mathrm{T}_{\mathrm{n} 2, \mathrm{n}}$ - Tempo de chegada do nariz da bolha $\mathbf{n}$ no canal 2;

$T_{c 1, n}$ - Tempo de chegada da cauda da bolha $\mathbf{n}$ no canal 1; 
$\mathrm{T}_{\mathrm{c} 2, \mathrm{n}}$ - Tempo de chegada da cauda da bolha $\mathbf{n}$ no canal 2;

$\mathrm{T}_{\mathrm{n} 1, \mathrm{n}+1^{-}}$Tempo de chegada do nariz da bolha $\mathbf{n + 1}$ no canal $\mathbf{1}$;

$\mathrm{T}_{\mathrm{n} 2, \mathrm{n}+1}$-Tempo de chegada do nariz da bolha $\mathbf{n + 1}$ no canal $\mathbf{2}$;

$\mathrm{T}_{\mathrm{c} 1, \mathrm{n}+1}$-Tempo de chegada da cauda da bolha $\mathbf{n} \mathbf{+ 1}$ no canal $\mathbf{1}$;

$T_{c 2, n+1}$-Tempo de chegada da cauda da bolha $\mathbf{n}+\mathbf{1}$ no canal 2 .

$\mathrm{U}$ - Velocidade das fases (líquida ou gasosa)

$\mathrm{u}_{\mathrm{b}}$ - Velocidade das bolhas dispersas

$\mathrm{u}_{\mathrm{d}}$ - Velocidade de deslizamento da bolha

$\mathrm{u}_{\mathrm{gf}}-$ Velocidade da fase gasosa

$\mathrm{U}_{\mathrm{GS}}$ - Velocidade superficial da fase gasosa

$\mathrm{u}_{\mathrm{Lf}}-$ Velocidade do líquido na região do filme

$\mathrm{u}_{\mathrm{LS}}$ - Velocidade média da fase líquida no pistão

$U_{L S}-$ Velocidade superficial da fase líquida

$U_{m}$ - Velocidade da mistura ou velocidade sem escorregamento

$u_{t}-$ Velocidade de propagação da bolha de gás

u'- Flutuação da velocidade na direção axial

$\mathrm{u}_{\mathrm{x}}$ - Componente axial da velocidade

$\mathrm{u}_{\mathrm{y}}$ - Componente transversal da velocidade

$\mathrm{u}(\mathrm{x}, \mathrm{y})$ - Magnitude da velocidade (resultante da velocidade axial e transversal)

$u_{x}^{*}(x, y)$ - Velocidade resultante do escoamento obtida a partir da subtração da velocidade na direção axial pela velocidade do nariz da bolha

$V_{b}$ - Velocidade da região traseira da bolha, segundo Cook \& Behnia 2000

$\mathrm{V}_{\mathrm{p}}$ - Velocidade do pistão.

$V_{t}$ - Velocidade da frente da bolha, definida segundo Cook \& Behnia 2000

v'- Flutuação da velocidade na direção transversal 


\section{Letras gregas}

$\alpha$ - Concentração volumétrica da fase líquida ou gasosa

$\alpha_{\llcorner}-$Hold-up da fase líquida

$\alpha_{G}-$ Fração de vazios

$\triangle \mathrm{P}$ - Perda de carga local

$\Delta \mathrm{t}$ - Intervalo de tempo

$v_{\mathrm{S}}$ - Freqüência de passagem dos slugs

$\lambda$ - Comprimento de onda

$\lambda_{L}-$ Hold up sem escorregamento

$\theta$ - Inclinação do tubo

$\sigma$ - Tensão superficial

$\Sigma$ - Parâmetro adimensional da tensão superficial

$\rho$ - Massa específica

$\kappa$ - Energia Cinética turbulenta

\section{Superescritos}

$v$ - Vertical

h - Horizontal

\section{Subscritos}

b - Bolha

c - Canal

$f$ - Filme

G - Gás

i - individual

L - Líquido

n - n-ésima bolha utilizada determinação dos parâmetros do escoamento

$\mathrm{n}+1$ - n-ésima primeira bolha utilizada determinação dos parâmetros do escoamento

p - Pistão

s - Pistão

u - Célula unitária

1 - canal 1

2 - canal 2 


\section{Siglas}

CCD - Charge Coupled Device

FFT - Transformada Rápida de Fourrier

LDV - Laser Doppler Velocimetry

LED - Light Emitting Diode

LIF - Laser Induced Fluorescence

PDF - Função Densidade de Probabilidade

PDA - Photochromic Dye Activation

PIV - Particle Image Velocimetry

PST - Pulsed Shadows Technique

RMS - Root Mean Square 